\title{
Conservation and Renewal of Ethnical Minority Group's Cultural Heritage in China: Case study of Master Planning and Design in Lingtang Town
}

\author{
Qingwen RONG ${ }^{1}$, a, Guoping XIONG ${ }^{1, b}$ \\ ${ }^{1}$ School of Architecture, Southeast University, Nanjing, China \\ arongqingwen88@126.com, b759488967@qq.com (corresponding author)
}

\begin{abstract}
Keywords: Hui, ethnical minority culture, architectural heritage, master planning, urban design
Abstract. Taking three Hui communities as cases, and basing on analysis on characteristics of urban space organizations and Islamic architecture in China, this paper seeks a method to promote conservation and renewal for ethnical minority group's cultural heritage by overall planning, protection on ecological environment, tourism planning, and conservation and design on ancient Mosque, old street and other cultural architectural heritage of the Hui People. Their living and activity places are also concerned. As a result, the historic buildings become key elements in promoting the rehabilitation and redevelopment of the whole area.
\end{abstract}

\section{Introduction}

Ethnical minority group's architectural heritage is an important part of world cultural heritage, and occupies a large proportion in China's national heritage. This kind of architectural heritage often has certain particularities: more prominent architectural images, symbolic functions and local characteristics. In addition, they always have close combinations with their surrounding residential areas, and in history they usually played a leading role in a certain rage of urban and rural spatial pattern. Therefore, with the rapid development of urbanization and rehabilitation of the old urban area in present China, it is of great significance to realize the importance of ethnical minority group's architectural heritage, and to research on the conservation and renewal mode of it and its surrounding areas.

There are 56 ethnic groups in China. The Hui People is one of the minority peoples with large population and most extensive distributions. According to the $6^{\text {th }}$ national census in China, the total number of Hui population is $10,586,087$, which gets the second place in the minority populations ${ }^{[1]}$. Also, the proportion of urban population of Hui People in its whole population has exceeded $31 \%$ by 2000. In other words, Hui People is "the most important urban ethnical minority group" in China ${ }^{[2]}$. Therefore, in the process of urbanization, protection of the architecture heritage of Hui People has a momentous significance. Further, Islamic mosques account for $25.18 \%$ of the existing religious activity places in China that are approved to open, and have a total number of about $35000^{[3]}$. In addition, there are also a large number of other Islamic worshiping places in urban and rural area, which are an important part of the religious activity places in China.

\section{The Characteristics of Autonomy Town of the Hui People and Islamic Architectures in China}

General Characteristics of Autonomy Towns and Communities of the Hui People in China A mosque in a Hui community is not only the center of religious activities such as praying and ceremony, but is also often used as Muslims' communication forum, and always combined with schools, monasteries and other public buildings. A mosque generally has a large space for accommodating Muslims, and is always located at the intersection of the main roads as an important node in urban and rural system. Further, the minarets in a mosque would commonly become a significant symbol in town due to their heights. Residential houses of Hui communities are generally built around the mosque, and always form separate living areas. Islam groups of different sects tend to reside in different districts in order to avoid sectarian conflicts, and in other cases community groups are likely to be set upon account of blood relationships. Bazaars are marketplaces of craftsmen and 
merchants, and usually become most popular places for public activities. Basically, the craftsmen's residential districts would develop around the bazaar.

Unique Characteristics of the Hui People Community and Islamic Architecture in China

The Chinese Muslims mainly include the Hui, the Uygur and other eight minority groups. In historical process, Islamic culture in China has been deeply influenced by traditional culture of the Han People, and consequently has some obvious characteristics of its own. "Jiao fang" (religious communities) is a kind of religious organization system with traditional Chinese characteristics, which formed between the Yuan and Ming Dynasties (1271 1644), only in the Hui communities ${ }^{[4]}$. From the perspective of spatial form, "Jiao fang" usually tends to be introverted, although their geographic boundaries seem to be able to be broken by other ethnic culture. In addition, since Islam was introduced into China, Islamic culture has constantly integrated with Chinese traditional Confucian culture. At the same time, the architecture form of the mosque has also gradually transformed from classical Middle-east Asian styles to forms that are more compounded with Chinese traditional architecture. In addition to common components like water rooms for body washing, lecture halls, mosques in China are apt to take Chinese traditional courtyard-form as their layout, which are symmetric with a central axis and has several courtyards arranged on the vertical axis. The mosques should face the Ka bah in Mecca, with the worshiping halls in mosques always sit in the west and face east. Further, various architecture forms have been shaped basing on the combination with Chinese traditional roof forms such as gable and hip roof and flush gable roof, which have obvious differences with the Islamic classical domes.

\section{Ling Tang Autonomy Town of the Hui People: Protection and Renewal in the Urban and Rural Master Planning}

The Ancient Mosque and Old Street in Ling Tang: Architectural Heritage in Continuous Development Ling Tang autonomy town of the Hui People is located in the Yangtze River Delta, northern part of Yangzhou, one of the National Historical and Cultural Cities in China. It is one of the most famous autonomy towns of the Hui People in China and also the only minority town in Jiangsu Province (Fig. 1), with a total area of 53 square kilometers. According to historical records, the introduction of Islamic culture probably began in Tang Dynasty, when a great number of Arabian businessmen came to Yangzhou. The starting time and development process of the Hui people's settlement and livelihood in Ling Tang generally align with those of Islamic culture's being introduced into China. Currently there are more than 7000 Muslim residents in Ling Tang, accounting for nearly one third of the total population.

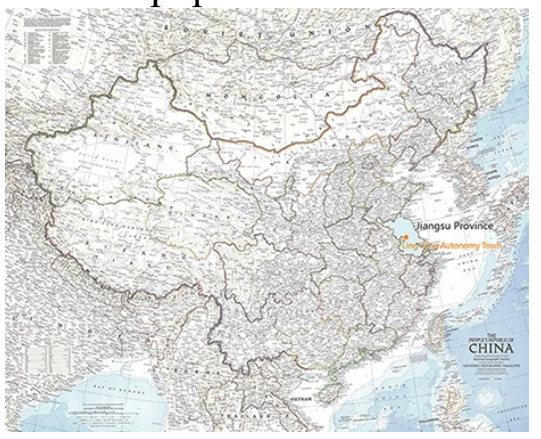

Fig.1 - location of Ling Tang autonomy town of the Hui People in Jiangsu Province, China

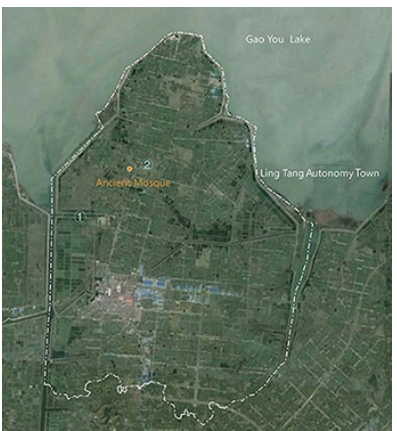

Fig.2 - location of the Ancient Mosque in Ling Tang

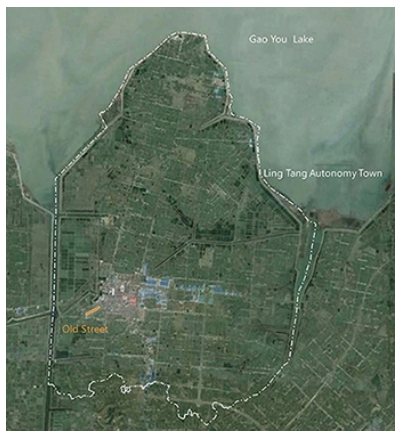

Fig.3 - location of the Old Street in Ling Tang

The Ancient Mosque is located in the northern part of the town (Fig. $2^{1}$ ). It was built in $15^{\text {th }} \sim 16^{\text {th }}$ century, and has changed locations twice. It was continuously reconstructed, expanded, added and conserved to meet sorts of requirements from the last several centuries up to now. Its size has been continually expanding, with its integrity, interior decorations and structures also gradually consummated. In history, people did not choose to keep the present situation for the conservation of the Mosque. On the contrary, constant renovation and restoration were encouraged, to make it gradually developed ${ }^{2}$. 
Religious function of the Mosque is integrated with other functions. For example, a primary school has ever been established in the wings, and the courtyards have once been used for Kungfu-training.

The Old Street was formed between Yuan and Ming Dynasties. It is located in the western part of the downtown, and is a historical street with traditional commercial type and distinctive public activity (Fig. 3). In $16^{\text {th }}$ century, there were many temples, monasteries and mansions on it. Now the total length of the street is about 760 meters. There are several characteristic public-activity nodes, such as a Kungfu training field, some municipal protect relics and traditional business stores on the street. The Kungfu training field is one of the main rally places of local Hui people to perform, take part in competitive sport and act in Chinese operas on festivals.

Ideas and Exploration of the Mater Planning

The master planning and urban design of Ling Tang autonomy town of the Hui People was carried on in two levels: the level of town region and the level of district and node.

First, for planning of the town region, the Hui distinctive industrial clusters were encouraged to be developed, such as processing industries associated with Muslim food and distinctive ecological agricultures. Colors and external forms of the new buildings were requested. Islamic buildings usually would choose white and green as their colors with arches, arcs and tooth forms as ornament elements. The planning proposed that new buildings especially the public buildings should follow the principles of not conflicting with existing traditional buildings.

Also, for protecting the tourism resources, the planning suggested that traffic connections with other cities and towns should be strengthen, and the water traffic should be included in the tour line planning as a new path. Five types of natural tourism resources and eight cultural tourism spots were chosen on the basic of colligation scores of historical value, integrity and ornamental value ${ }^{3}$. (Fig. 4)

Besides, for promoting the quality of ecological environment, the original natural environment and ethnic living places were conserved in the planning by protection zoning. The ecological aquaculture industry was supposed to be combined with the lakes and crop varieties of both economic benefits and ornamental values were encouraged. (Fig. 5)

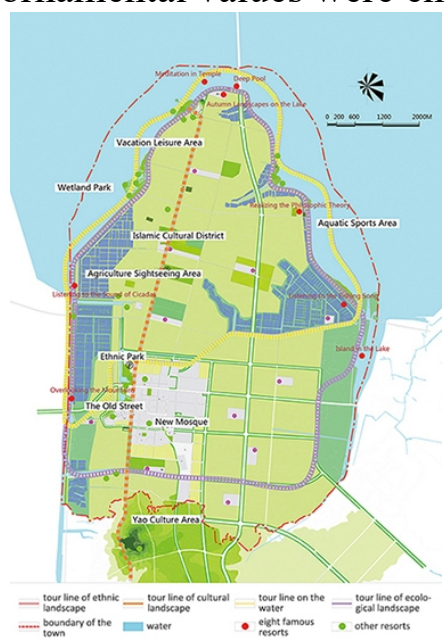

Fig.4 - planning of tour lines and sites

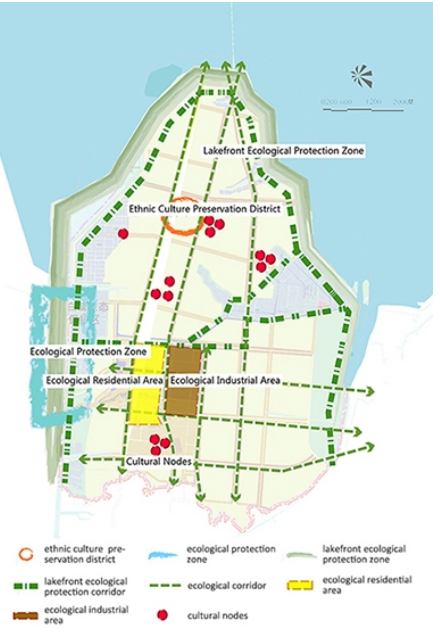

Fig.5 - protection planning of ecological environment

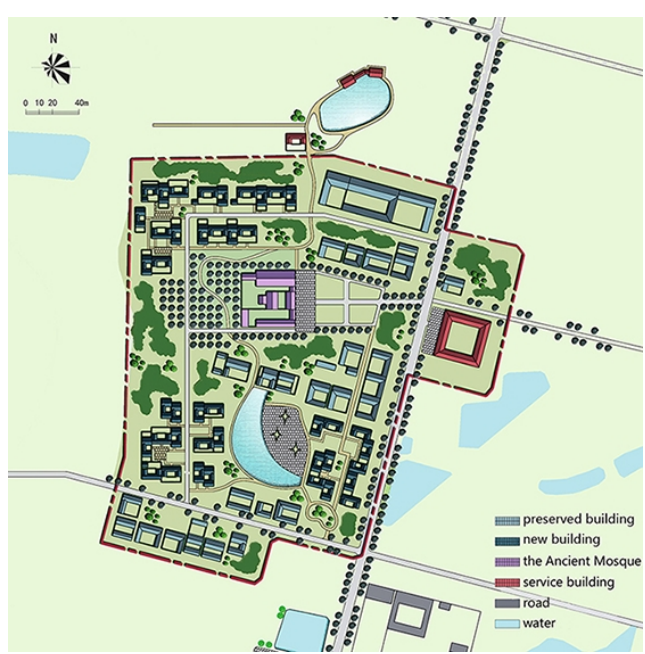

Fig.6 - general layout design of areas surrounding the Ancient Mosque

Second, for planning of districts and nodes, conservation of the Ancient Mosque itself was required to strictly abide by the Law of the People's Republic of China on Protection of Cultural Relics (2015). 1.01 hectares of its surrounding areas was identified as "core protection zone", while 6.14 hectares as "folk-custom experience area". The styles and heights of the new architectures were controlled in the design to conserve the Mosque's role as a land mark. The disused factory on the north was transformed into workshops of local handicrafts, while a Muslim food court which was representative for Hui custom was newly built. The Hui communities' residential custom of "settling around the Mosque" was taken into account, including the local residents' habit of building their houses along the roads. (Fig. 6)

Besides, for conservation and renovation of the Old Street, the master planning formulated measures for protecting the historical buildings, taking renovations on other existing buildings, and 
formulating a guide for the control of new buildings. The goal was to promote the development of traditional business and to form a traditional commercial centre in downtown area. The elements that formed the traditional features were required to be entirely protected, including door bars, steles, old trees, street textures, folk cultures, etc. Buildings around the Kungfu-training field were reconstructed to form a main commercial zone, and most of the existing industrial buildings were removed or renovated to make room for public spaces. (Fig. 7)

Further, for master planning and urban design of the downtown, inherent characteristic signs of Hui were strengthened in the design, for example, arched doors and windows, domes, dentiform walls and other elements were encouraged to be widely used. The landscape viewing corridors to mountains in the south were protected. (Fig. 8)

Tourism Planning on the Principles of Community Engagement

An operation way of local Muslim family management and community participation was accepted in the organization of supporting facilities for tourism. Tourist products and tour lines were planned under closely collaboration with local Muslim community, so that the community's participation could be promoted and the understanding of the religious and cultural identity could be made more widely.

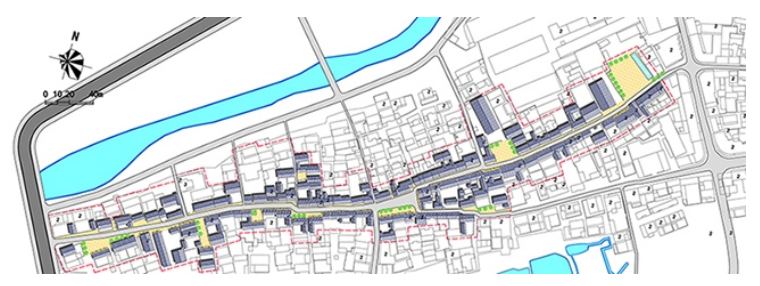

Fig.7 - general layout design of the Old Street

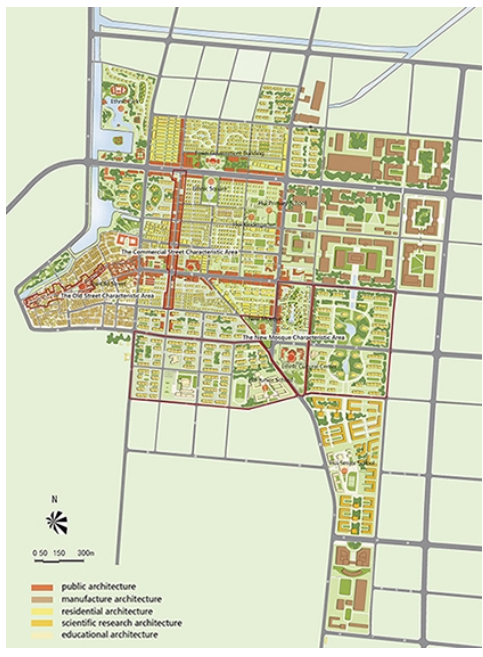

Fig.8 - general layout design of the downtown

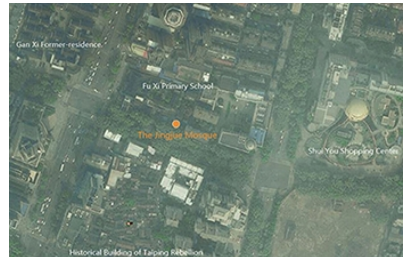

Fig.9 - surroundings of the Jingjue Mosque

\section{Two more cases: the Jingjue Mosque and the Jizhaoying Mosque in Nanjing}

The other two cases are the Jingjue Mosque (Fig. 9) and the Jizhaoying Mosque in Nanjing. Both them are located in the old residential areas, beside the newly developed business areas.

The Jingjue Mosque is the earliest and largest one in the existing mosques in Nanjing. It was built in $14^{\text {th }}$ century and reconstructed in $15^{\text {th }}$ century. Another reconstruction was taken in $19^{\text {th }}$ century and the existing building is built in the late Qing Dynasty. As a provincial protected relics unit, it has been conserved under strict law in recent year ${ }^{4}$. Similarly, the Hui people in Nanjing formed "Jiao fang" in the early Qing Dynasty ${ }^{[5]}$. The Hui community associated with the Jingjue Mosque and other three adjacent mosques is the famous "Qi Jia Wan" community ${ }^{5}$. At present in the process of urban development and renewal, the model of Hui people for inhabiting as an ethnic group has gradually changed to a mode of living scattered. The renovation design at the end of $2007^{6}$ conserved the original framework and architectural pattern. At the same time, the whole building was strengthened and raised to improve its structure, drainage system and ventilation system.

At present the Jingjue Mosque is located closely next to a main road and most of the buildings around it are commercial shops. Its traditional forms are confronted with challenges of continued rapid urban renewal. In order to solve the problem, the master planning and the specific planning fully considered the relationships between the Mosque and Gan Xi Former Residence, which is a famous historical building close to it. Renovations and controls of heights and styles of surrounding buildings were required in 
these planning. Municipal infrastructures were demanded to be improved in organic renewals. A special department of conservation and construction was assigned to be responsible for the conservation. In addition, the planning suggested that static conservation of the cultural heritage should be combined with dynamic urban industries and this combination would bring beneficial impacts on the development of surrounding commercial, cultural, tourism and other industries.

The Jizhaoying Mosque was built in $18^{\text {th }}$ century and reconstructed in early $20^{\text {th }}$ century, with a Hui primary school ever located in it (in 1929). At present it is the only mosque inside the northern part of Nanjing city. The Yu Shi Street in Changjing Lou Community where it is located is a bustling area with a large number of Hui people settling. The new Jizhaoying Mosque was just totally rebuilt in a new style, reflecting the Muslim characteristic in a modern way. The design paid enough attention to the relationship between the building and its site. Continuous distance was kept from the building to the boundary of the road in order to meet the requirements of superior planning. And a form of "open ground-floor space" was used in the design to offer public spaces to the citizens ${ }^{[6]}$. In addition, the new mosque was connected to the old one through courtyards so that natural landscapes could be introduced into the building. Arabic calligraphy was used as the source of decoration elements. Islamic culture characteristics were emphasized by these elements and building materials.

The organic integration of the above two cases' functions and architectural styles with modern urban context has made them become more important places for both indigenous residents and tourists.

\section{Conclusions: Conservation and Renewal Strategies of Ethnical Minority Culture and Their Heritage in Urban and Rural Master Planning}

China's ethnical minority culture and their heritage are experiencing a new development period in modern urban and rural space. On one hand they are usually confronted with the rapid renewal of surrounding environment. On the other hand, because of their uniqueness, a certain proportion of them are under a dynamic process of constant reconstructions and renovations to meet requirements of eras. We should fully realize this process.

The following points are suggested to be paid attention to:

First, as a "social product", the ethnical architectural heritage formed in certain time and certain places has experienced a long and tortuous process, and is comprised of many historical layers. Therefore, intensive reading, digging of the historical and cultural information is the basis for scientific conservation. Conservation should not be stop at a static congealing mode. It is necessary to inherit and innovate living morphology basing on observation of the ethnic culture, religious norms, spatial forms and structure characteristics, as well as to fully represent features of the architectural heritage. In addition, relationships between heritage and its surrounding environment should be paid enough attention to, so that coordinate spatial forms and exciting public spaces could be set up.

Second, for the architectural heritage that has been completely or mostly disappeared, indication by distinctive identifications combining with the new functions in modern cities or towns may help to strengthen the expression of its representative image in space and to wake up the memory of certain community and ethnic groups. Through the construction of some cultural projects in cities or towns which could form an organic connection with the existing architectural heritage and urban public space, planners may successfully construct cultural atmosphere and converse the architectural heritage into a kind of "cultural capital".

Third, basing on respect on local living traditions and cultural features, maintaining and expanding community-participation traditional cultural activities, with cultivating and developing characteristic industry types on the combination of local characteristics would be an important part in master planning. Architectural heritage is supposed to keep the control on modern life while carrying historic information.

Fourth, regulations are suggested to be given to the conservations of heritage and surrounding constructions according to the implement contents of current master planning. Conservation levels and timing should be classified in accordance with the status of the heritage and the urgency degrees 
of protecting, so that prospective protections and constructions in each coming period would have clear goals and plans.

\section{Acknowledgements}

This work was financially supported by the Fundamental Research Funds for the Central Universities and Research Innovation Program for College Graduates of Jiangsu Province (Grant No. KYLX15_0052), Scientific Research Foundation of Graduate School of Southeast University (Grant No. 3201005704).

The project of "Master Planning and Urban Design of Ling Tang Autonomy Town of the Hui People" was directed by Prof. Guoping XIONG from Southeast University. Hui TIAN, Mingzhi CHEN, Yang YANG, Yixi SHEN, Xin TIAN, Wei WANG and more other persons were involved in this project and provided important help for this paper. The authors would like to express cordial thanks to them.

\section{Notes}

1 (1),(2) in Fig.2 show the initial location in 15th -16th century and reconstruction site in 16th century.

2 The relocation and rebuilt during $16^{\text {th }}$ century expanded the size with wings added. After the second rebuilt in $19^{\text {th }}$ century and the reconstruction in early 20th century wings, reception rooms and a screen wall were added. The mosque was seriously demolished during the "Cultural Revolution". After that gradual reconstructions and renovations were taken on the main buildings with the stone carving and water rooms restored so that the original appearance could be basically recovered.

3 There are five kinds of natural resources in Ling Tang, including mountains, wetlands, lakes, woodlands and farmlands. Representative landscapes are selected. In addition, there are also eight major places of historic figures and cultural heritage, including Ancient Mosque, Cemetery of the Hui people, Ethnic Park, the Old Street, and so on.

${ }^{4}$ It was included in the ancient buildings' conservation plan in 2008. In the renovation the original historical pattern was kept.

5 "Qi Jia Wan" community is one of the major birth places of the cultural movement of Hui in China which has a far-reaching influence. And because of this, the community has had a strong psychological identification among the Hui people.

${ }^{6}$ The renovation design was made by Architectural Design and Research Institute of Southeast University.

\section{References}

[1] Information on http://www.stats.gov.cn/tjsj/pcsj/rkpc/6rp/indexch.htm (website of National Bureau of Statistics of the People's Republic of China) (In Chinese)

[2] Xuefeng MA, Chuanbin ZHOU: A paradigm discussion on social structure of urban Hui Muslim minority: As the case of Beijing. Journal of Hui Muslim Minority Study, 2010, p. 33-39. (In Chinese)

[3] Information on http:/www.sara.gov.cn//ldxx/wza/ldjh/20109.htm (website of State Bureau of Religious of the People's Republic of China - statistic done in 2012) (In Chinese)

[4] Yongping ZONG: Research on religious community of the Hui people of China. Journal of Chifeng University (Soc. Sci), 2012, 33(6), p. 35-38. (In Chinese)

[5] Li XUE: From tradition to modern: The ethnic intermarriage conception research about the floating population in Nanjing Hui. Master Thesis of Northwest University for Nationalities, 2010, C91, p. 22-27. (In Chinese)

[6] Huiying SUN: The architectural design strategies of contemporary mosque in China: Taking the rebuilding project of Nanjing Jizhaoying Mosque as an example. Architecture \& Culture, 2011, 8(2), p. 90-91. (In Chinese) 